\title{
THE
}

\section{Influence of Environmental Stress on Biomass Partitioning in Transgenic Tobacco Plants Expressing the Movement Protein of Tobacco Mosaic Virus}

\author{
S. Balachandran \\ Richard J. Hull \\ University of Rhode Island, rjhull@uri.edu \\ R. A. Martins \\ Y. Vaadia \\ W. J. Lucas
}

Follow this and additional works at: https://digitalcommons.uri.edu/pls_facpubs

Terms of Use

All rights reserved under copyright.

\section{Citation/Publisher Attribution}

Balachandra, S., Hull, R. J., Martins, R. A., Vaadia, Y., \& Lucas, W. J. Influence of Environmental Stress on Biomass Partitioning in Transgenic Tobacco Plants Expressing the Movement Protein of Tobacco Mosaic Virus. Plant Physiology, 114(2), 475-481. doi: 10.1104/pp.114.2.475

Available at: https://doi.org/10.1104/pp.114.2.475

This Article is brought to you for free and open access by the Plant Sciences and Entomology at DigitalCommons@URI. It has been accepted for inclusion in Plant Sciences and Entomology Faculty Publications by an authorized administrator of DigitalCommons@URI. For more information, please contact digitalcommonsgroup@uri.edu. 


\title{
Influence of Environmental Stress on Biomass Partitioning in Transgenic Tobacco Plants Expressing the Movement Protein of Tobacco Mosaic Virus ${ }^{1}$
}

\author{
Suchandra Balachandran², Richard J. Hull, Rosemary A. Martins, Yoash Vaadia, and William J. Lucas* \\ Section of Plant Biology, Division of Biological Sciences, University of California, Davis, California 95616 (S.B., \\ R.A.M., W.J.L.); Department of Plant Sciences, College of Resource Development, University of Rhode Island, \\ Kingston, Rhode Island 02881 (R.J.H.); and Department of Plant Sciences, The Hebrew University of Jerusalem, \\ Jerusalem 91904, Israel (Y.V.)
}

The influence of various environmental factors on biomass partitioning between shoots and roots in transgenic tobacco (Nicotiana tabacum) plants expressing the movement protein (MP) of tobacco mosaic virus (TMV) was investigated. TMV-MP-expressing transgenic plants exhibited a root-to-shoot ratio that was approximately $40 \%$ below that of transgenic vector control plants. When transgenic plants expressing the TMV-MP were subjected to water-stress conditions, the root-to-shoot ratio was increased to a value comparable to that of control plants subjected to the same water-stress treatment. Although the root-to-shoot ratio was increased by $\mathrm{N}$ or $P$ deficiencies, the TMV-MP-induced alteration in biomass partitioning was not overcome. Surprisingly, under $\mathrm{K}^{+}$-deficient growth conditions, both TMV-MP-expressing and control plants exhibited reduced root-to-shoot ratios when compared with plants grown in the presence of sufficient $\mathrm{K}^{+}$. Furthermore, plant growth under $\mathrm{K}^{+}$-deficient conditions did not alleviate the influence of the TMV-MP over resource allocation to the roots. These results are discussed in terms of possible mechanisms by which stress signals could cause an alteration in biomass partitioning between shoots and roots in control and transgenic tobacco plants expressing the TMV-MP.

Transgenic tobacco (Nicotiana tabacum) plants expressing the MP of TMV exhibit an increase in sugar and starch levels within mature leaves, as well as a reduction in partitioning of biomass to roots, when compared with vector control plants (Lucas et al., 1993; Balachandran et al., 1995; Olesinski et al., 1995). The mechanism(s) through which the TMV-MP affects carbon allocation and biomass partitioning in transgenic tobacco plants has yet to be elucidated. It is well established that in TMV-MPexpressing transgenic tobacco plants plasmodesmal SEL is increased from control values of $800 \mathrm{D}$ to greater than 9.4 kD (Wolf et al., 1989; Ding et al., 1992). Although it was

${ }^{1}$ This work was supported by United States-Israel Binational Agricultural Research and Development Fund grant no. IS-238594C (W.J.L.), and National Science Foundation grant no. IBN-946974 (W.J.L.).

${ }^{2}$ Present address: Department of Biological Sciences, University of Wollongong, Wollongong, NSW 2522, Australia.

*Corresponding author; e-mail wjlucas@ucdavis.edu; fax 1916-752-5410. hypothesized that this TMV-MP-induced increase in SEL would result in the enhanced export of fixed carbon out of source leaves, translocation during the photoperiod was actually decreased, with a concomitant increase in the levels of sugar and starch (Olesinski et al., 1995). Transgenic tobacco plants expressing TMV-MP mutants, in which the domain responsible for the increase in plasmodesmal SEL was deleted, further demonstrated that the effect of the TMV-MP on carbon allocation and biomass partitioning was independent of its influence over plasmodesmal SEL (Balachandran et al., 1995). Studies in which a temperaturesensitive mutant of TMV was employed confirmed that the effect of the TMV-MP on SEL was independent of its effects on carbon allocation (Olesinski et al., 1995).

A hypothesis advanced to account for the TMV-MPinduced changes in carbon partitioning and allocation suggests that the TMV-MP interferes with an endogenous signal transduction pathway involved in regulating biomass partitioning between shoots and roots (Balachandran et al., 1995; Lucas et al., 1996). Partitioning of photosynthetically fixed carbon among various organs of a plant depends on the physiological and developmental stages of the organs, and it is well known that environmental growth conditions can influence this partitioning (Wardlaw, 1990; Geiger and Servaites, 1991; Mooney and Winner, 1991). However, the integrated regulatory mechanisms involved in root-to-shoot communication remain to be elucidated (Wardlaw, 1990). In this regard, TMV-MP-expressing tobacco plants appear to represent an ideal experimental system on which to study the control mechanisms involved in biomass partitioning within the plant.

In response to environmental cues, plants readjust partitioning of photosynthates to maintain a functional equilibrium between shoot and root growth, since they are interdependent (Mooney and Winner, 1991). In this study we investigated the effects of environmental factors such as water stress and nutrient deficiency $\left(\mathrm{N}, \mathrm{P}\right.$, and $\left.\mathrm{K}^{+}\right)$, both well known to influence biomass partitioning between roots and shoots, on TMV-MP-expressing tobacco plants. Under the imposed stress, total plant dry weight was re-

Abbreviations: MP, movement protein; SEL, size exclusion limit; TMV, tobacco mosaic virus. 
duced and the plant responded by partitioning more biomass to its root system (control and TMV-MP lines). Water stress was found to override completely the influence of the TMV-MP over the root-to-shoot ratio. However, imposed nutrient deficiency conditions did not overcome the MP effect. These results are discussed in terms of possible mechanisms by which stress signals could cause an alteration in biomass partitioning between shoots and roots in control and transgenic tobacco plants expressing the TMV-MP.

\section{MATERIALS AND METHODS}

\section{Plant Material and Biomass Measurements}

Transgenic tobacco (Nicotiana tabacum) line 277 expressing the TMV-MP and vector control line 306 (plasmid vector only) were provided by Dr. Roger Beachy of the Scripps Institute (La Jolla, CA). We chose one line of transgenic tobacco plant for the present experiments, since previous studies with a number of independent transformed lines clearly established that expression of the TMV-MP reduces biomass partitioning to roots and alters carbon allocation in all of these transgenic plants (Lucas et al., 1993; Balachandran et al., 1995; Olesinski et al., 1995). Seeds were germinated on a soil mixture and 4-week-old seedlings were transplanted into plastic pots containing sand. These seedlings were grown for 2 more weeks before water stress was imposed, because the small 4 -week-old plants were not expected to survive the stress condition. In nutrient deficiency studies 5-week-old seedlings were transferred to glass jars containing the appropriate hydroponic culture medium $\left(\mathrm{N}, \mathrm{P}\right.$, and $\left.\mathrm{K}^{+}\right)$. Plants were either grown in a greenhouse or growth chamber, as described below for specific experiments. At the end of each treatment, plants were harvested, separated into leaves, stems, and roots, and dried in a $70^{\circ} \mathrm{C}$ oven for $72 \mathrm{~h}$. Root-to-shoot ratios were calculated for each plant based on dry weight. Significance between treatment means was determined by analysis of variance.

\section{Water-Stress Treatments}

Six-week-old transgenic tobacco plant lines 277 and 306 were subjected to water stress by withholding water on alternate days. These water-stressed plants received $2 \times$ Hoagland solution (Hoagland and Arnold, 1938) once on alternate days, whereas well-watered controls received $1 / 2 \times$ Hoagland solution twice daily; in each situation, water delivery raised the soil to field capacity. Plants were grown in the greenhouse during mid-summer under a 16-h photoperiod. Light intensity at midday was adjusted to 1200 to $1500 \mu \mathrm{mol} \mathrm{m} \mathrm{m}^{-2} \mathrm{~s}^{-1}$, whereas in the morning and evening the values ranged between 700 and $950 \mu \mathrm{mol} \mathrm{m} \mathrm{m}^{-2} \mathrm{~s}^{-1}$. The temperature regime in the greenhouse was $30^{\circ} \mathrm{C} \pm 2.0 /$ $22^{\circ} \mathrm{C} \pm 2.0$, day/night. Water-stressed plants exhibited severe wilting of mature leaves and this stress condition was imposed for 23 to $25 \mathrm{~d}$, after which time the plants were harvested to determine dry matter partitioning.
Water-stress studies were repeated three times, and results of one representative experiment are reported.

\section{Nutrient-Stress Treatments}

In N-stress experiments, 5-week-old transgenic tobacco lines 277 and 306 were grown in 1-L glass jars filled with a nutrient solution containing $8 \mathrm{~mm}$ (high), $5 \mathrm{~mm}$ (moderate), $2 \mathrm{~mm}$ (low), or $0.5 \mathrm{~mm}$ (very low) nitrate-N. All other macro- and micronutrients were maintained at control levels (Lucas et al., 1993). All nutrient solutions were aerated and replaced every other day. Replacement of nutrients every other day was sufficient for plants supplied with both adequate and deficient nutrients. Under nutrientdeficient conditions, the nutrient solution was depleted very slowly by both genotypes, thus MP-transgenic plants did not experience less nutrient stress than the control line. Plants were grown in a greenhouse under early autumn conditions. The natural photoperiod $(10 \mathrm{~h}$; intensity, $1200-$ $1500 \mu \mathrm{mol} \mathrm{m} \mathrm{m}^{-2} \mathrm{~s}^{-1}$ ) was extended using high-intensity metal halide lamps $\left(600-700 \mu \mathrm{mol} \mathrm{m}{ }^{-2} \mathrm{~s}^{-1}\right)$ for an additional $4 \mathrm{~h}$. Plants were grown for $25 \mathrm{~d}$ under the specified $\mathrm{N}$ regime and then harvested to determine dry matter partitioning, at which time they were $60 \mathrm{~d}$ old. These experiments were repeated three times, and results of one representative experiment are reported. Photosynthetic rates were measured on leaf numbers 4 or 5 (leaf 1 being the last leaf to attain $5 \mathrm{~cm}$ in length) of high- and low-Ngrown plants, as described in Balachandran et al. (1995).

$\mathrm{P}$ and $\mathrm{K}^{+}$experiments were carried out essentially as described for N-stress studies, except that plants were grown in a controlled environment chamber (model PGV36, Conviron, Permbina, ND; $28^{\circ} \mathrm{C} / 22^{\circ} \mathrm{C}$, day/night temperatures with $\mathrm{RH}$ maintained at $70 \%$ ). Light intensity (metal halide lamps) at the beginning $(2 \mathrm{~h})$ and end $(2 \mathrm{~h})$ of a 14-h photoperiod was set at 100 to $150 \mu \mathrm{mol} \mathrm{m} \mathrm{m}^{-2} \mathrm{~s}^{-1}$ (at canopy level), whereas in the middle of the period it was increased to 500 to $600 \mu \mathrm{mol} \mathrm{m} \mathrm{m}^{-2} \mathrm{~s}^{-1}$. Two nutrient levels were used in these studies: $1 \mathrm{~mm}$ (high) and $0.05 \mathrm{~mm}$ (low), and $7 \mathrm{~mm}$ (high) and $0.5 \mathrm{~mm}$ (low). Plants were harvested 25 to $27 \mathrm{~d}$ after treatment initiation and analyzed for dry matter partitioning. These experiments were repeated twice and representative results from one experiment are reported. Photosynthetic rates were measured on leaf numbers 4 or 5 of high- and low-P-grown plants, as described in Balachandran et al. (1995).

\section{RESULTS}

\section{Effect of Water Stress on Biomass Partitioning}

Consistent with our earlier studies (Lucas et al., 1993; Balachandran et al., 1995), under well-watered conditions the biomass of TMV-MP-expressing tobacco plants (line 277) was reduced in comparison with vector control (line 306) plants. From the data presented in Table I, it is clear that the major effects of the TMV-MP are exerted on the stem and root tissues, with the latter being reduced to $40 \%$ of the root mass present in control plants. As a consequence, plant line 277 had a root-to-shoot ratio that was 
Table I. Influence of water stress on biomass partitioning in transgenic tobacco plant expressing the plasmid vector control (line 306) and the TMV-MP (line 277)

Data represent means \pm SE $(n=6)$.

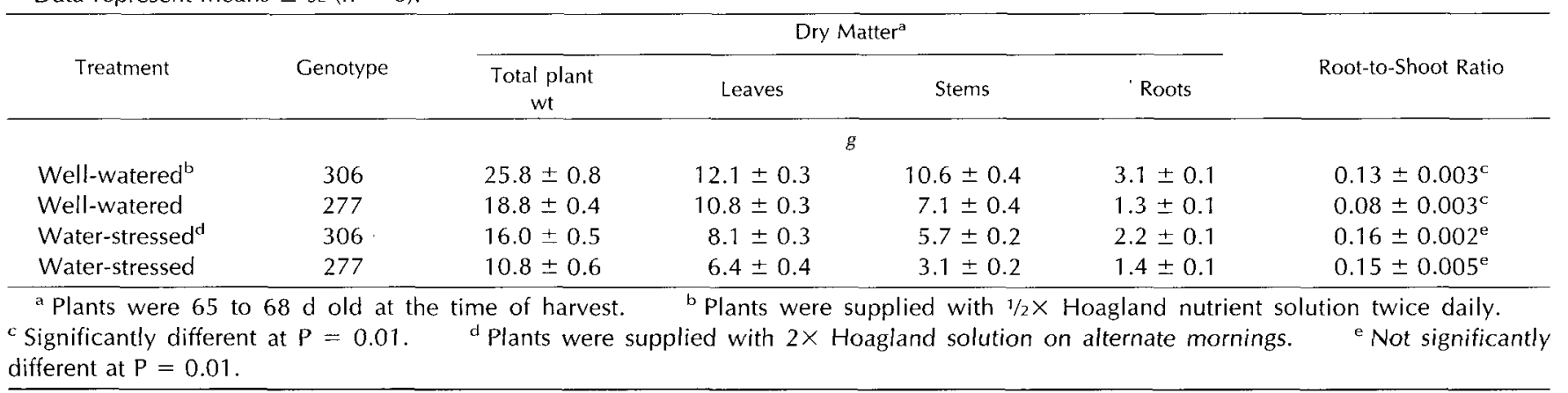

$38 \%$ smaller than the value measured for plant line 306 . We have previously established that the decrease in root-toshoot ratio in TMV-MP-expressing tobacco plants, when compared with control plants, is observed at various developmental stages between the two genotypes (Lucas et al., 1993). Under the water-stress regime employed in the present experiments, in which the turgor within source leaves was allowed to decline to the point where these leaves underwent wilting, overall growth of both plant lines (277 and 306) was reduced to approximately $60 \%$ of that observed under well-watered conditions (Table I). It is interesting that, whereas root biomass of water-stressed control plants decreased by $30 \%$, the value remained unaltered in plant line 277. As a consequence of this differential response to the imposed water stress, the root-to-shoot ratio in plant line 277 increased to a value comparable to that measured in control line 306. These results, confirmed in three separate experiments, established that water stress results in the activation of a signal that can completely override the effect of the TMV-MP in terms of negating its influence over biomass partitioning to the root.

\section{Effect of $\mathbf{N}$ Stress on Biomass Partitioning}

As expected, growth of plant lines 306 and 277 decreased as $\mathrm{N}$ availability was lowered (Table II). Reducing the available $\mathrm{N}$ from 8 to $5 \mathrm{~mm}$ had little effect on leaf, stem, or root biomass, whereas in the presence of 2.0 or $0.5 \mathrm{~mm} \mathrm{~N}$, total plant biomass was reduced significantly (Table II). (Low-N plants exhibited chlorotic leaves, and plant height and leaf number were reduced in both lines [data not shown].) Under 0.5 and $2.0 \mathrm{~mm} \mathrm{~N}$ conditions, biomass partitioning to the roots was reduced less than partitioning to above-ground organs, such that root-to-shoot ratios increased in both lines 306 and 277, when compared with plants that received 5 and $8 \mathrm{~mm} \mathrm{~N}$. The $\mathrm{N}$-deficiencyinduced shift in carbon partitioning to the roots of control line 306 resulted in a $70 \%$ increase in the root-to-shoot ratio ( 0.5 or $2 \mathrm{~mm}$ compared with 5-M-grown plants). A similar response was detected for plant line 277 , with the increase being 100 and $83 \%$ higher under 0.5 and $2.0 \mathrm{~mm} \mathrm{~N}$, respectively, compared with $5 \mathrm{~mm} \mathrm{~N}$ conditions. The important finding from these studies was that even though $N$ deficiency induced an increase in the root-to-shoot ratio in TMV-MP-expressing plants, in contrast to the situation with water stress, this form of nutrient stress failed to relieve the influence of the TMV-MP over resource allocation to the roots. This can be seen by comparing root-toshoot ratios for plant lines 306 and 277 measured on plants grown under the four $\mathrm{N}$ levels. For the $0.5,2,5$, and $8 \mathrm{~mm}$ $\mathrm{N}$ cultures, root biomass was consistently lower in the

Table II. Influence of $N$ deficiency on biomass partitioning in transgenic tobacco expressing the plasmid vector control (line 306 ) and the TMV-MP (line 277)

Data represent means \pm SE $(n=6)$.

\begin{tabular}{|c|c|c|c|c|c|c|}
\hline Treatment & Genotype & \multicolumn{4}{|c|}{ Dry Matter } & Root-to-Shoot Ratio \\
\hline $8 \mathrm{~mm}$ Nitrate & 306 & $15.8 \pm 1.1$ & $8.7 \pm 0.7$ & $5.8 \pm 0.5$ & $1.4 \pm 0.1$ & $0.10 \pm 0.005^{b}$ \\
\hline $8 \mathrm{~mm}$ Nitrate & 277 & $9.5 \pm 0.5$ & $6.2 \pm 0.4$ & $2.7 \pm 0.2$ & $0.6 \pm 0.06$ & $0.07 \pm 0.004^{\mathrm{b}}$ \\
\hline $5 \mathrm{~mm}$ Nitrate & 306 & $13.2 \pm 0.5$ & $7.4 \pm 0.4$ & $4.7 \pm 0.5$ & $1.2 \pm 0.1$ & $0.10 \pm 0.006^{b}$ \\
\hline $2 \mathrm{~mm}$ Nitrate & 277 & $5.5 \pm 0.8$ & $3.6 \pm 0.4$ & $1.3 \pm 0.2$ & $0.5 \pm 0.06$ & $0.11 \pm 0.01^{\mathrm{c}}$ \\
\hline $0.5 \mathrm{~mm}$ Nitrate & 306 & $4.9 \pm 0.4$ & $2.8 \pm 0.4$ & $1.3 \pm 0.3$ & $0.7 \pm 0.06$ & $0.17 \pm 0.008^{c}$ \\
\hline $0.5 \mathrm{~mm}$ Nitrate & 277 & $2.7 \pm 0.4$ & $1.7 \pm 0.3$ & $0.7 \pm 0.13$ & $0.3 \pm 0.04$ & $0.12 \pm 0.007^{c}$ \\
\hline
\end{tabular}

\footnotetext{
a Plants were $60 \mathrm{~d}$ old at the time of harvest. $\quad{ }^{\mathrm{b}}$ Significantly different at $\mathrm{P}=0.05 . \quad{ }^{\mathrm{c}}$ Significantly different at $\mathrm{P}=0.001$.
} 
TMV-MP-expressing line when compared with the vector control line (Fig. 1), and the root-to-shoot ratios for line 277 plants were smaller than those of the equivalent line 306 plants by $30,40,35$, and $30 \%$, respectively.

Under N-deficient conditions, photosynthetic rates of leaves of control tobacco plants were only $25 \%$ of those grown with high-N nutrition (Table III). Previously, it has been observed that the photosynthetic rates were comparable between the transgenic line expressing the MP and the vector control line under adequate nutrition (Lucas et al., 1993). Our present studies confirm those results and show that even under $\mathrm{N}$-deficient conditions, the photosynthetic rates were similar between the two lines (Table III).

\section{Influence of P Stress on Biomass Partitioning}

Under low-P nutrition, plant growth was similarly reduced in tobacco lines 306 and 277 (Table IV). (LowP-grown plants were reduced in height and number of leaves [data not shown], but they did not display signs of chlorosis.) It is important to note that, for both plant lines, root growth under low- and high-P conditions was identical. Consequently, root-to-shoot ratios underwent a considerable increase in response to reduced levels of available $\mathrm{P}$, being 83 and 55\% higher in lines 306 and 277, respectively. However, under this imposed $\mathrm{P}$ stress, the root-to-shoot ratio for line 277 still remained $36 \%$ below that of control line 306. Thus, both $\mathrm{N}$ and $\mathrm{P}$ deficiencies elicited a relative increase in carbon allocation to the root system, but these responses did not override the effects of the TMV-MP. As in the case of $\mathrm{N}$ nutrition studies, under low-P conditions the photosynthetic rates were comparable between both transgenic tobacco lines 277 and 306, being reduced to $60 \%$ of the equivalent lines grown at high-P conditions (Table III).

\section{Influence of $\mathrm{K}^{+}$Deficiency on Biomass Partitioning}

Total plant weight, leaf, stem, and root growth were all reduced in tobacco plants grown under $0.1 \mathrm{mM} \mathrm{K}^{+}$(Table $\mathrm{V}$ ); except for early senescence of lower leaves, deficiency symptoms were not visible on these plants. Biomass parti-

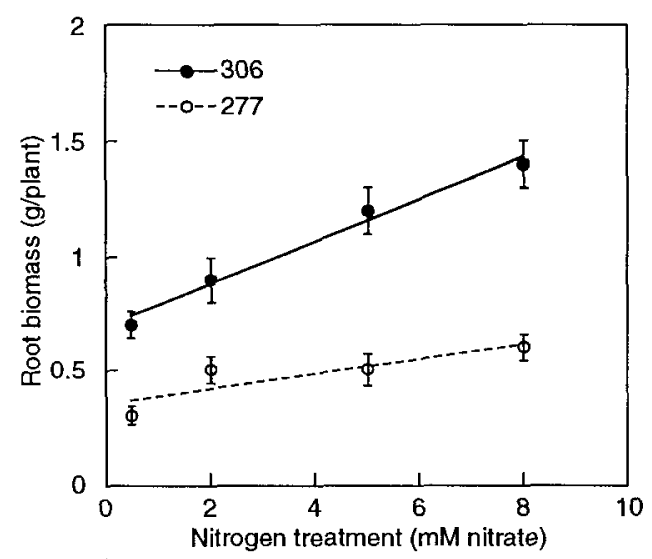

Figure 1. Relationship between root biomass and $N$ supply for experiments performed using transgenic tobacco plants expressing the TMV-MP (line 277) and vector control plants (line 306).
Table III. Photosynthetic rates of mature source leaves of high-Nand high-P-, low-N-, and low-P-grown transgenic tobacco plants expressing the plasmid vector control (line 306) and the TMV-MP (line 277)

Data represent means $\pm \mathrm{SE}(n=4-8)$.

\begin{tabular}{cccc}
\hline \multirow{3}{*}{ Genotype } & \multicolumn{3}{c}{ Photosynthetic Rate $^{\mathrm{a}}$} \\
\cline { 2 - 4 } & $\begin{array}{c}\text { High nitrate and } \\
\text { high phosphate }^{\mathrm{b}}\end{array}$ & Low nitrate & Low phosphate \\
\hline & \multicolumn{3}{c}{$\mathrm{mol} \mathrm{CO}_{2} \mathrm{~m}^{-2} \mathrm{~s}^{-1}$} \\
306 & $12.8 \pm 0.2$ & $3.3 \pm 0.1$ & $8.3 \pm 0.4$ \\
277 & $12.3 \pm 0.3$ & $3.5 \pm 0.1$ & $7.1 \pm 0.5$ \\
\hline
\end{tabular}

a Photosynthetic rate was measured 2 to $4 \mathrm{~d}$ before harvesting the plants for biomass partitioning studies. ${ }^{b}$ Plants were supplied with $8 \mathrm{~mm}$ nitrate and $1 \mathrm{~mm}$ phosphate. c,d Plants were supplied with $0.5 \mathrm{~mm}$ nitrate and $0.05 \mathrm{~mm}$ phosphate, respectively.

tioning to the roots was more reduced under these low- $\mathrm{K}^{+}$ nutrient conditions, than was partitioning to the shoots. Hence, in these experiments, root-to-shoot ratios actually decreased in plant lines 306 and 277 . However, as observed under both $\mathrm{N}$ and $\mathrm{P}$ deficiencies, the root-to-shoot ratio of plant line 277 remained $30 \%$ smaller than control line 306 plants grown in $0.1 \mathrm{~mm} \mathrm{~K} \mathrm{~K}^{+}$.

\section{DISCUSSION}

Transgenic tobacco lines expressing the TMV-MP have been extensively characterized with respect to biomass allocation, carbon export from source leaves, and sugar and starch accumulation in leaves of various ages (Lucas et al., 1993; Balachandran et al., 1995; Olesinski et al., 1995). The reduction in root-to-shoot ratio in TMV-MP-expressing tobacco plants, when compared with vector control plants, has been observed at different developmental stages of the plant (Lucas et al., 1993). The aim of the present study was to determine whether the activation of stress-related signals could influence the effects of the TMV-MP on resource allocation in transgenic tobacco plants. The discussion will be confined to this context, with due recognition of the extensive literature pertaining to the interaction between water/nutrient stress and the matrix of effects on both physiological and developmental processes, including adjustments to the set-point for control over the root-to-shoot ratio of such stressed plants (Thornley, 1972; Radin and Eidenbock, 1984; Wilson, 1988; Fredeen et al., 1989; Davies et al., 1990; Mooney and Winner, 1991; Qiu and Israel, 1992; Bano et al., 1993).

Based on the data presented in this study, we have established that the imposition of water stress on TMV-MPexpressing tobacco plants can alleviate the influence exerted by the TMV-MP over carbon allocation to the roots. Under the water-stress regime employed in the present experiments, total biomass production was reduced equally (to $60 \%$ of the well-watered controls) in TMV-MPexpressing and vector control plants (Table I). However, the pattern of biomass partitioning was altered significantly in water-stressed tobacco plants expressing the TMV-MP. The increase in the root-to-shoot ratio that occurred in these water-stress experiments was achieved by a 
Table IV. Influence of $P$ deficiency on biomass partitioning in transgenic tobacco expressing the plasmid vector control (line 306) and the TMV-MP (line 277)

Data represent means $\pm S E(n=6)$.

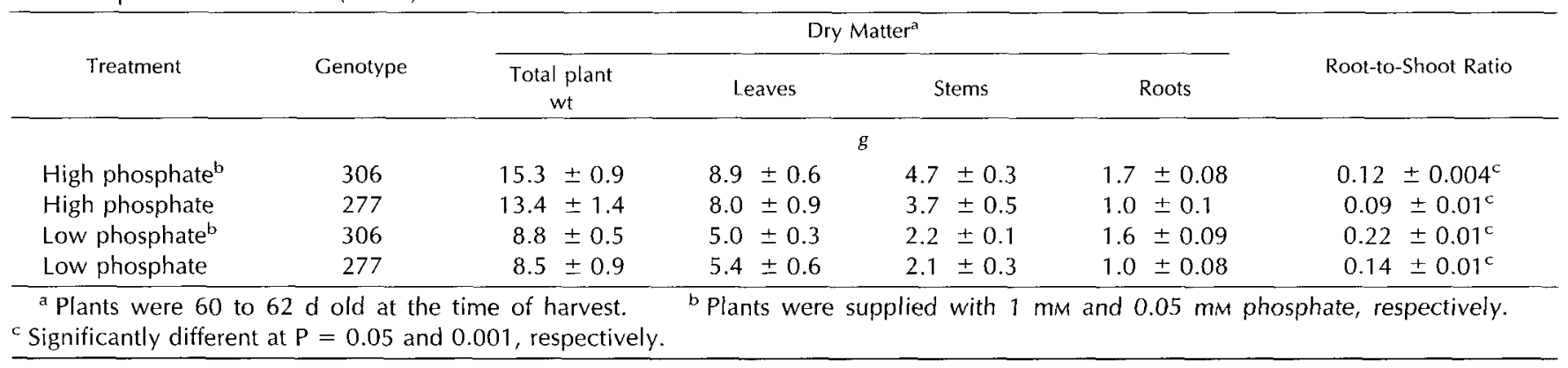

shift in resources from the stems to the root system. This can be seen by comparing the percentage of dry matter partitioned to the stems and roots of these plants under control (well-watered) and water stress growth conditions. Under control conditions, $38 \%$ of the total plant dry weight was present in the stems, with only $7 \%$ in the roots; stem and root values for plant line 306 were 41 and $12 \%$, respectively. In contrast, under water-stress conditions, only $29 \%$ of the total plant dry weight was present in the stems, whereas $13 \%$ was present in the roots; stem and root values for plant line 306 were 37 and 14\%, respectively.

It is important to note that, although water stress caused the anticipated reduction in total leaf biomass, both lines of stressed plants retained approximately the same level of biomass partitioning in the leaves (shoots) as occurred in the well-watered treatments. This suggests that the tobacco plant may utilize two carbon pools: one that delivers resources to the vegetative meristem and leaves (shootassociated pool), and a second that serves the stem and root systems. Although we have established that the imposition of water stress activates (or alters) a signal transduction cascade that can override the influence of the TMV-MP over resource allocation to the roots, the components of this pathway have yet to be elucidated.

The complexity of the interaction between the TMV-MP and the endogenous resource control network(s) is further illustrated by our finding that water stress failed to override the TMV-MP-induced increase in carbon allocation to the shoot-associated pool. For example, of the total plant biomass produced under well-watered conditions, plant line 306 allocated $47 \%$ to this pool, whereas the value for plant line 277 was $57 \%$ (see leaf dry matter in Table I); under water-stress conditions the values were 50 and $60 \%$, respectively. The earlier studies that we performed on transgenic tobacco lines expressing mutant forms of the TMV-MP established that the TMV-MP is responsible for the observed changes in allocation to these two pools (Balachandran et al., 1995). Deletion of the C-terminal 10 amino acids from the TMV-MP had no effect on its ability to increase plasmodesmal SEL or perform its other viralrelated functions; however, biomass partitioning to leaves, stems, and roots in plants expressing this mutant MP was identical to plant line 306.

Imposed $N$ and $P$ deficiencies also elicited a shift in resource allocation that gave rise to an increase in the root-to-shoot ratio (Tables II and IV). As observed for water-stressed tobacco plants, this increase was achieved by a shift in the allocation of resources from the stem to the roots. In the $\mathrm{N}$ experiments this shift in resource allocation appeared to involve a threshold level of available $\mathrm{N}$, in that plant lines 306 and 277 grown under 5 or $8 \mathrm{~mm} \mathrm{~N}$ partitioned 9 and $6 \%$ of their total biomass to their roots, respectively, whereas under 0.5 or $2 \mathrm{~mm} \mathrm{~N}$ the values were 14 and $9 \%$, respectively (Table II). It is interesting that under P-stress conditions, root growth was maintained at the same level observed in plants supplied with sufficient $\mathrm{P}$, whereas leaf and stem growth were reduced. This suggests that the factors regulating biomass partitioning to roots are

Table V. Influence of $\mathrm{K}^{+}$deficiency on biomass partitioning in transgenic tobacco expressing the plasmid vector control (line 306$)$ and the TMV-MP (line 277)

Data represent means \pm SE $(n=6)$.

\begin{tabular}{|c|c|c|c|c|c|c|}
\hline \multirow[b]{2}{*}{ Treatment } & \multirow[b]{2}{*}{ Genotype } & \multicolumn{4}{|c|}{ Dry Matter ${ }^{\mathrm{a}}$} & \multirow[b]{2}{*}{ Root-to-Shoot Ratio } \\
\hline & & $\begin{array}{l}\text { Total plant } \\
\text { wt }\end{array}$ & Leaves & Stems & Roots & \\
\hline \multicolumn{7}{|c|}{$g$} \\
\hline High $\mathrm{K}^{+\mathrm{b}}$ & 306 & $14.2 \pm 0.6$ & $7.2 \pm 0.4$ & $5.3 \pm 0.3$ & $1.7 \pm 0.04$ & $0.14 \pm 0.003^{\mathrm{c}}$ \\
\hline High $\mathrm{K}^{+}$ & 277 & $12.3 \pm 0.7$ & $6.7 \pm 0.5$ & $4.6 \pm 0.3$ & $1.0 \pm 0.05$ & $0.09 \pm 0.004^{\mathrm{c}}$ \\
\hline Low $\mathrm{K}^{+\mathrm{b}}$ & 306 & $9.8 \pm 0.4$ & $5.3 \pm 0.3$ & $3.7 \pm 0.1$ & $0.8 \pm 0.06$ & $0.09 \pm 0.005^{c}$ \\
\hline Low $\mathrm{K}^{+}$ & 277 & $8.2 \pm 0.4$ & $4.6 \pm 0.3$ & $3.1 \pm 0.1$ & $0.5 \pm 0.03$ & $0.06 \pm 0.004^{c}$ \\
\hline \multicolumn{3}{|c|}{$\begin{array}{l}\text { a Plants were } 60 \text { to } 62 \mathrm{~d} \text { old at the time of harvest. } \\
\text { fferent at } P=0.001 \text { and } 0.01 \text {, respectively. }\end{array}$} & b Plants wer & ed with $7 \mathrm{~m}$ & $0.01 \mathrm{mM} \mathrm{K}^{+}$ & c Significantly \\
\hline
\end{tabular}


either spatially or functionally separated from those involved in biomass partitioning to the vegetative meristem and leaves (shoot system).

The influence of the TMV-MP, in terms of increasing the proportion of biomass allocation to the vegetative meristem and leaves, was similarly unaffected by a nutrient deficiency of either $\mathrm{N}$ or $\mathrm{P}$ (Tables II and IV). The physiological limitations imposed by growing plants under 0.5 compared with $8 \mathrm{~mm} \mathrm{~N}$ is illustrated by the significant reduction in total plant weight for the low- $\mathrm{N}$ situation $(30 \%$ of $8 \mathrm{~mm} \mathrm{~N}$-grown plants). The constancy of the effect of the TMV-MP on the allocation between the two carbon pools may reflect an endogenous target site that serves a crucial role in the resource signaling cascade. Clearly, the input from this signal must be at a higher level than signals produced in response to nutrient deficiency. On this same theme, the inability of line $277 \mathrm{~N}$ - and P-stressed plants to reset their root-to-shoot ratios to control values likely reflects the hierarchical position of the TMV-MP-associated signal relative to nutrient-stress-induced signals.

The reduction in biomass partitioning to roots in TMV MP-expressing plants is not due to an alteration in carbon allocation into starch that is then re-allocated preferentially to the young, growing leaves (Huber, 1983), because the levels of sugars and starch in young, growing leaves were comparable between the transgenic line expressing the MP and the control line (Lucas et al., 1993). During the onset of $\mathrm{N}$ deficiency, new leaf initiation and expansion were much more sensitive to leaf $\mathrm{N}$ than was photosynthesis, and therefore more carbohydrates would have become available for export to the roots (Tolley-Henry and Raper, 1986, 1991). Photosynthetic rates of source leaves of transgenic tobacco plants expressing the TMV-MP and vector control plants were comparable under nutrient-deficient $(\mathrm{N}$ and $\mathrm{P}$ ) conditions (Table III). Similarly, under high-nutrient conditions, photosynthetic rates were not significantly different between lines 277 and 306 (Lucas et al., 1993). Although the root-to-shoot ratio is increased in MP-expressing transgenic plants grown under low- $\mathrm{N}$, compared with high- $\mathrm{N}$ grown plants, biomass partitioning to the roots was still lower than that of low- $\mathrm{N}$-grown control plants. Therefore, the mechanisms through which carbon supply to the roots was reduced in TMV-MP-expressing plants supplied with high $\mathrm{N}$ must still prevail during growth under deficient $\mathrm{N}$ conditions.

Our $\mathrm{K}^{+}$-deficiency experiments yielded interesting results. Under limiting $\mathrm{K}^{+}$conditions, biomass partitioning to the roots was reduced, with a concomitant decrease in root-to-shoot ratios compared with the same plant lines grown under a high level of $\mathrm{K}^{+}$. A reduced root-to-shoot ratio in low $-\mathrm{K}^{+}$-grown plants has been reported previously (Cakmak et al., 1994a). This effect might be related to the enhancement of photoassimilate export, which occurs when high levels of $\mathrm{K}^{+}$are present in source leaves (Conti and Geiger, 1982; Cakmak et al., 1994b). Plants grown under low- $\mathrm{K}^{+}$levels would likely have reduced $\mathrm{K}^{+}$concentrations in their source leaves, which could retard the rate of phloem loading, thereby leading to the observed reduction in export in $\mathrm{K}^{+}$-stressed tobacco plant lines 306 and 277. The data presented in Table $\mathrm{V}$ indicate that such a change in export must have occurred in a preferential manner, since a reduction in carbon partitioning was detected only in the roots. Finally, the root-to-shoot ratio of TMV-MP-expressing plants remained approximately $30 \%$ below that of low- $\mathrm{K}^{+}$-grown vector control plants. Because similar results were obtained in N- and P-deficiency experiments, it is probably safe to assume that all nutrientdeficiency signals involved in readjusting resource allocation at the whole-plant level act at a level below that of the TMV-MP.

\section{Plant Control over Resource Allocation}

Clearly, plants have evolved efficient signaling systems that operate between shoots and roots to control developmental and physiological processes occurring within these physically separated organs. Although much is known in terms of the manner in which this signaling network permits the plant to interact with and respond to environmental input signals, very little is known in terms of the specific molecular constituents that comprise this "long-range" signaling pathway. Obviously, certain hormones that are synthesized in the root and then translocated via the xylem translocation stream to their site of action in the shoot (Vaadia and Itai, 1969; Wilson 1988; Farrar, 1992) represent one form of input signal (for review, see Jackson [1997]). Likewise, hormones moving in the phloem could establish a communication link between source leaves and developing plant organs. However, the established complexity of the resource allocation system of the plant, including recent findings that source leaves in some way control direction and levels of allocation to specific tissues (Minchin et al., 1994; Balachandran et al., 1995), implicate the involvement of novel signaling molecules.

We recently advanced the hypothesis that macromolecules (proteins or ribonucleo-protein complexes) may act as signal molecules in controlling biomass partitioning in plants (Balachandran et al., 1995; Lucas et al., 1996; Wolf and Lucas, 1997). This model was based on the recent findings that specific viral and plant proteins have the ability to move from cell to cell via plasmodesmata (Lucas and Gilbertson, 1994; Lucas et al., 1995). Now, it has also been established that the 100 or more proteins present in the enucleate sieve elements of the higher plant phloem (Fisher et al., 1992) have the capacity to interact with plasmodesmata to mediate their own cell-to-cell transport (S. Balachandran, Y. Xiang, W.J. Lucas, unpublished results). These findings support the hypothesis that plasmodesmal trafficking of macromolecules could establish a dual-level information network, which functions between the companion cell-sieve element system and the neighboring mesophyll (local regulation) and distant organs (long-distance regulation via the phloem translocation stream) (for review, see Lucas et al. [1996]; Wolf and Lucas, 1996). Such a system, in conjunction with the normal array of plant hormones, may permit the plant to control its developmental and physiological processes at a supracellular level. The challenge will be to develop appropriate methods to identify the components of the signaling pathway involved in 
regulating resource partitioning at the whole-plant level (Stitt, 1996).

\section{ACKNOWLEDGMENTS}

Y.V. was on sabbatical leave from the Hebrew University of Jerusalem, Israel. We thank Shmuel Wolf for helpful discussions during this study.

Received December 2, 1996; accepted February 20, 1997. Copyright Clearance Center: 0032-0889/97/114/0475/07.

\section{LITERATURE CITED}

Balachandran S, Hull RJ, Vaadia Y, Wolf S, Lucas WJ (1995) Alteration in carbon partitioning induced by the movement protein of tobacco mosaic virus originates in the mesophyll and is independent of change in plasmodesmal size exclusion limit. Plant Cell Environ 18: 834-844

Bano A, Dorffling K, Bettin D, Hahn H (1993) Abscisic acid and cytokinins as possible signals in xylem sap of rice plants in drying soil. Aust J Plant Physiol 20: 109-115

Cakmak I, Hengeler C, Marschner H (1994a) Partitioning of shoot and root dry matter and carbohydrates in bean plants suffering from phosphorus, potassium and magnesium deficiency. J Exp Bot 45: 1245-1250

Cakmak I, Hengeler C, Marschner H (1994b) Changes in phloem export of sucrose in leaves in response to phosphorus, potassium and magnesium deficiency in bean plants. J Exp Bot 45: 1251-1257

Conti TR, Geiger DR (1982) Potassium nutrition and translocation in sugar beet. Plant Physiol 70: 168-172

Davies WJ, Mansfield TA, Hetherington AM (1990) Sensing of soil water status and the regulation of plant growth and development. Plant Cell Environ 13: 709-719

Ding B, Haudenshield JS, Hull RJ, Wolf S, Beachy RN, Lucas WJ (1992) Secondary plasmodesmata are specific sites of localization of the tobacco mosaic virus movement protein in transgenic tobacco plants. Plant Cell 4: 915-928

Farrar JF (1992) The whole plant: carbon partitioning during development. In CJ Pollock, JF Farrar, AJ Gordon, eds, Carbon Partitioning within and between Organisms. BIOS Scientific Publishers, Oxford, UK, pp 163-179

Fisher DB, Wu Y, Ku MSB (1992) Turnover of soluble proteins in the wheat sieve tube. Plant Physiol 100: 1433-1441

Fredeen AL, Rao IM, Terry N (1989) Influence of phosphorus nutrition on growth and carbon partitioning in Glycine max. Plant Physiol 89: 225-230

Geiger DR, Servaites JS (1991) Carbon allocation and response to stress. In HA Mooney, WE Winner, EJ Pell, eds, Response of Plants to Multiple Stresses. Academic Press, New York, pp 103-127

Hoagland DR, Arnold DI (1938) The water culture method for growing plants without soil. Calif Agric Exp Stn Cir 357: 1-39

Huber SC (1983) Relation between photosynthetic starch formation and dry weight partitioning between the shoot and root. Can J Bot 61: 2709-2716
Jackson M (1997) Hormones from roots as signals for the shoots of stressed plants. Trends Plant Sci 2: 22-28

Lucas WJ, Balachandran S, Park J, Wolf S (1996) Plasmodesmal companion cell-mesophyll communication in the control over carbon metabolism and phloem transport: insights gained from viral movement proteins. J Exp Bot 47: 1119-1128

Lucas WJ, Bouché-Pillon S, Jackson DP, Nguyen L, Baker L, Ding B, Hake S (1995) Selective trafficking of KNOTTED-1. homeodomain protein and its mRNA through plasmodesmata. Science 270: 1980-1983

Lucas WJ, Gilbertson RL (1994) Plasmodesmata in relation to viral movement within leaf tissue. Annu Rev Phytopathol 32: 387-341

Lucas WJ, Olesinski A, Hull RJ, Haudenshield JS, Deom CM, Beachy RN, Wolf S (1993) Influence of tobacco mosaic virus 30-kDa movement protein on carbon metabolism and photosynthate partitioning in transgenic tobacco plants. Planta 190: 88-96

Minchin PEH, Thorpe MR, Farrar JF (1994) Short-term control of root-to-shoot partitioning. J Exp Bot 45: 615-622

Mooney HA, Winner WE (1991) Partitioning response of plants to stress. In HA Mooney, WE Winner, EJ Pell, eds, Response of Plants to Multiple Stresses. Academic Press, New York, pp 129-141

Olesinski A, Lucas WJ, Galun E, Wolf S (1995) Pleiotropic effects of tobacco-mosaic-virus movement protein on carbon metabolism in transgenic tobacco plants. Planta 197: 118-126

Qiu J, Israel DW (1992) Diurnal starch accumulation and utilization in phosphorus-deficient soybean plants. Plant Physiol 98: 316-323

Radin JW, Eidenbock MP (1984) Hydraulic conductance as a factor limiting leaf expansion of phosphorus-deficient cotton plants. Plant Physiol 75: 372-377

Stitt M (1996) Plasmodesmata play an essential role in sucrose export from leaves: a step toward an integration of metabolic biochemistry and cell biology. Plant Cell 8: 565-571

Thornley JHM (1972) A balanced quantitative model for root: shoot ratios in vegetative plants. Ann Bot 36: 431-441

Tolley-Henry L, Raper CD (1986) Expansion and photosynthetic rates of leaves of soybean plants during onset of and recovery from nitrogen stress. Bot Gaz. 147: 400-406

Tolley-Henry L, Raper CD (1991) Soluble carbohydrate allocation to roots, photosynthetic rate of leaves, and nitrate assimilation as affected by nitrogen stress and irradiance. Bot Gaz 152: 23-33

Vaadia Y, Itai C (1969) Interrelationships of growth with reference to the distribution of growth substances. In WJ Whittington, ed, Root Growth. Butterworths, London, pp 65-77

Wardlaw IF (1990) The control of carbon partitioning in plants. New Phytol 116: 341-381

Wilson JB (1988) A review of evidence on the control of shoot:root ratio, in relation to models. Ann Bot 61: 433-449

Wolf S, Deom CM, Beachy RN, Lucas WJ (1989) Movement protein of tobacco mosaic virus modifies plasmodesmal size exclusion limit. Science 246: 377-379

Wolf S, Lucas, WJ (1997) Plasmodesmal-mediated plant communication network: Implications for controlling carbon metabolism and resource allocation. In Foyer $\mathrm{CH}$, Quick P, eds, Engineering Improved Carbon and Nitrogen Use Efficiency in Higher Plants. Taylor and Francis, London 